\title{
IMPROVEMENT OF REFRACTORY PERIPHERAL EDEMA WITH MULTILAYERED COMPRESSION BANDAGING: A CASE REPORT
}

\author{
Jegy M. Tennison, MD, Jack B. Fu, MD, Ying Guo, MD, Eduardo Bruera, MD \\ Department of Palliative, Rehabilitation, and Integrative Medicine, \\ The University of Texas MD Anderson Cancer Center, Houston, TX
}

\section{BACKGROUND AND PURPOSE}

Lower extremity edema, which can be caused by several factors, is often poorly managed with commonly prescribed compression stockings and diuretics.

Diuretics are often erroneously given in all forms of edema and may cause problems because their long-term application may induce chronicity of the edema due to disturbance of the renin-angiotensin relationship.

- Compression therapy, although effective against venous edema, is widely underused.

\section{CASE DESCRIPTION}

A 64-year-old man with a history of hypertension, coronary artery disease, psoriasis, and multiple myeloma was admitted to the hospital for neutropenic fever, right lower extremity (RLE) cellulitis, bilateral lower extremity (BLE) weakness, RLE pain, and significant BLE edema.

The patient was treated with cefepime and vancomycin for his RLE cellulitis and pneumonia.

His physical examination was significant for $3+$ pitting BLE edema, decreased light touch sensation to RLE distally, 3/5 strength to RLE, and 4/5 strength to lower left extremity.

Improvement of his RLE cellulitis was noted.

For his BLE edema, he received furosemide $(40 \mathrm{mg}$ daily) and was prescribed compression stockings.

Magnetic resonance imaging demonstrated stable thoracic compression compared with prior imaging scans, as well as a chronic lumbosacral synovial cyst.

An electrodiagnostic study showed active and chronic lumbosacral radiculopathy affecting multiple nerve roots, along with mild axonal sensory and, to a lesser extent, motor symmetric peripheral neuropathy in the lower extremities.

BLE venous Doppler ultrasonography revealed no deep vein thrombosis, and the patient's ankle brachial index and toe brachial index were within normal range.

The patient continued to have BLE weakness with long phases of immobile sitting, with resultant significant BLE edema and fatigue, which affected his gait and daily activities.

A physiatrist evaluated factors that contributed to the patient's lower functional independence measure (FIM) scores and determined that the patient needed an intense rehabilitation program in an interdisciplinary setting; thus, he was transferred to the acute inpatient rehabilitation unit.

- The patient was referred to a lymphedema-certified therapist to apply lower extremity multilayered compression bandaging owing to severe edema that was refractory to treatment with diuretics.

Nonadhesive elastic bandages (Elastomull; BSN Medical, Charlotte, NC) were applied circumferentially to all toes.

- A tubular bandage (Tricofix; BSN Medical) was applied from the metatarsal heads to the infrapatellar region.

A 12-cm foam bandage (CompriFoam; BSN Medical) was applied from the metatarsal heads to the infrapatellar region.

- $\quad$ An 8-cm short-stretch compression bandage (Comprilan; BSN Medical) was applied in a figure- 8 pattern over the ankle, and a $10-\mathrm{cm}$ Comprilan compression bandage was applied from the calf to the infrapatellar region with compression decreasing proximally.

Table 1. Bilateral lower extremity circumference measurements $(\mathrm{cm})$ with compression bandaging

\begin{tabular}{|c|c|c|c|c|c|}
\hline & Day 1 & Day 2 & Day 3 & Day 7 & $\begin{array}{l}\text { Change } \\
\text { (day 7-day 1) }\end{array}$ \\
\hline $\begin{array}{l}\text { Right } \\
\text { MTP }\end{array}$ & 27.0 & 24.4 & 23.0 & 23.0 & $4(15 \%)$ \\
\hline $\begin{array}{l}\text { Right } \\
\text { ankle }\end{array}$ & 27.0 & 25.2 & 23.0 & 23.0 & $4(\mathbf{1 5 \%})$ \\
\hline $\begin{array}{l}20 \mathrm{~cm} \\
\text { below } \\
\text { right knee }\end{array}$ & 44.5 & 40.7 & 38.7 & 37.2 & $7.3(\mathbf{1 6 \%})$ \\
\hline $\begin{array}{l}\text { Right } \\
\text { knee }\end{array}$ & 45.0 & 43.5 & 41.4 & 41.4 & $3.6(\mathbf{8 \%})$ \\
\hline Left MTP & 26.0 & 24.5 & 22.7 & 23.0 & $3(12 \%)$ \\
\hline Left ankle & 26.5 & 24.2 & 23.1 & 23.0 & $3.5(13 \%)$ \\
\hline $\begin{array}{l}20 \mathrm{~cm} \\
\text { below left } \\
\text { knee }\end{array}$ & 43.0 & 38.4 & 36.2 & 37.2 & $5.8(13 \%)$ \\
\hline Left knee & 44.4 & 43.4 & 40.0 & 40.0 & $4.4(\mathbf{1 0} \%)$ \\
\hline
\end{tabular}

Abbreviation: MTP, metatarsophalangeal joint

\section{OUTCOMES}

- The patient's limb circumference measurements improved, as noted in Table 1.

- His FIM scores for locomotion improved from requiring maximum assistance to ambulate 80 feet on day 1 of compression therapy to requiring only contact-guard assistance to ambulate 170 feet on day 8 .

- His weight and body mass index (BMI) improved from $94.5 \mathrm{~kg}$ (BMI 36) on day 1 of compression therapy to $86.3 \mathrm{~kg}$ (BMI 33) on day 7.

- The patient consistently reported no leg pain or shortness of breath on days when he received compression bandaging by the certified lymphedema therapist.

- The patient's albumin $(3.7 \mathrm{~g} / \mathrm{dL})$, blood urea nitrogen (14 $\mathrm{mg} / \mathrm{dL})$, and creatinine $(0.83-0.90 \mu \mathrm{mol} / \mathrm{L})$ levels were within normal limits when he received compression bandaging.

- Once the BLE edema significantly improved, he was fitted with $20-30 \mathrm{~mm} / \mathrm{Hg}$ compression stockings.

\section{DISCUSSION}

- $\quad$ This case demonstrates the utility of multilayered compression bandaging, typically used in the management of lymphedema, in the control of peripheral edema refractory to diuretic therapy.

- In our case, the patient was originally prescribed compression stockings, which are commonly used to treat lower extremity edema.

- However, it is often difficult to fit patients who have severe edema with appropriately sized compression stockings, so clinicians should be vigilant about using alternative treatment options for severe and refractory lower extremity edema.

- $\quad$ Patients who are unable to fit into a compression stocking owing to severe edema should be referred to a certified lymphedema therapist for appropriate compression therapy options.

- Before application of compression bandaging, patients should receive a full assessment of the extent of edema level of mobility, and any allergies and neurological, cardiac, and skin conditions. ${ }^{1}$
Severe arterial occlusive disease is a contraindication for compression therapy. ${ }^{2}$

- Compression bandages must be applied by trained personnel $^{2,3}$ and changed according to the degree of drainage.

- Lower extremity ischemia can develop if compression bandages are applied too tightly; therefore, patients should be instructed to remove the bandage if discoloration of the toes, numbness, or tingling occurs. $^{2}$

- The choice of initial compression therapy (elastic, inelastic, single layer, or multilayer) is based on numerous factors, including pain level, patient compliance, the presence and size of venous ulcers, and the availability of resources (e.g., trained personnel who can apply and reapply complex bandaging systems). ${ }^{2}$

- In general, bandages are used to treat venous disease ulceration ${ }^{1}$ and lower extremity edema, ${ }^{4}$ and compression stockings are used to prevent recurrence after the ulcer has healed ${ }^{1}$ and once swelling is reduced. ${ }^{4}$

- Documenting serial limb circumference measurements and weight are essential outcome measurement tools with compression bandaging.

More research is necessary to identify the most effective combination of physical therapy, compression therapy, and pharmacologic treatment for patients with multiple comorbidities.

\section{REFERENCES}

1) Fletcher J, Moffatt C, Partsch H, Vowden K, Vowden P. Principles of Compression in Venous Disease. A Practitioner's Guide to Treatment And Prevention of Venous Leg Ulcers. London: Wounds International; 2013. http://www.woundsinternational.com/best-practices/view/principles-ofcompression-in-venous-disease-a-practitioners-guide-to-treatment-andprevention-of-venous-leg-ulcers. Accessed April 10, 2018. 2) Armstrong D, Meyer A. Compression therapy for the treatment of chronic venous insufficiency. Mills JL, Eidt JF, ed. UpToDate. Waltham, MA: UpToDate Inc. http://www.uptodate.com. Accessed April 16, 2018. 3) O'Meara SCN, Nelson EA, Dumville JC. Compression for venous leg ulcers. Cochrane Database Syst Rev. 2012;11:CD000265.

4) M. Ca 4) Mosti G, Partsch H. Bandages or double stockings for the initial therapy of venous oedema? A randomized, controlled pilot study. Eur J Vasc Endovasc
Surg. 2013;46:142-148. 